\title{
Development of Irregularity Index Based on Dynamic Characteristics to Quantify the Vertical Geometric Irregularities
}

\author{
H.M.S.C. Rathnasiri, J.A.S.C. Jayasinghe and C.S. Bandara
}

\begin{abstract}
Most of the high-rise buildings in the modern era are irregular in shape due to architectural and aesthetic requirements. But the performance of such buildings during an earthquake varies with the degree of irregularity. According to past studies, the degree of irregularity can be quantified using the parameters based on the geometric configuration of the building and based on dynamic characteristics as well. Two types of geometric irregularities that can be identified in the high-rise buildings are vertical geometric irregularity and horizontal geometric irregularity. However, the present study is focused on vertical geometric irregularity only. The fundamental mode base shear is a kind of dynamic parameter considered in the present study to propose a new index for quantifying the degree of irregularity in selected vertically irregular RC buildings. The study also compares the performance of the existing methods on quantifying the degree of irregularity for the selected irregular buildings. Selected irregular buildings are modeled as planer concrete momentresisting frames using SAP2000 and analyzed for modal analysis. The proposed index can easily quantify the degree of irregularity in vertically irregular RC moment-resisting frames compared to the existing irregularity quantification methods.
\end{abstract}

Keywords: Base shear, High rise buildings, Modal analysis, RC frames, Vertical irregularity

\section{Introduction}

Skyscrapers have been a long part of the urban cityscapes nowadays. Limitations of the land and cost of the land have made the vertical construction much more convenient than linear development. Most of the high-rise buildings that were built in the past are regular throughout its elevation. However, most of the high-rise buildings nowadays are becoming irregular due to architectural and aesthetic requirements. Complex architectural forms chosen by the architects introduce structural irregularities that adversely affect the safety of the building against earthquake and wind loading. Since earthquake and wind-induced forces play an important role in the design of high-rise buildings, choosing an appropriate structural system can mitigate the adverse dynamic effects on the design of high-rise buildings. Performance of the multistory frame buildings against earthquake loading depends on the distribution of mass, stiffness, and strength in both horizontal and vertical planes. Therefore, non-uniform distribution of mass, stiffness, and strength leads to form structural weaknesses in buildings, and damages from the earthquakes are initiated from the locations where these structural weaknesses are present. Therefore, a significant amount of research attention has been received to evaluate the performance of vertical and horizontal irregular buildings. Georgouss is et al.[1], Le-Trung et al.[2], Michalis et al.[3], Karavasilis et al.[4], Roy \& Mahato [5], Sarkar et al.[6], Varadharajan et al.[7], Bhosale et al.[8], Rajeev and Tesfamariam [9] are some of the past studies that evaluate the performance of the irregular buildings against the earthquake loading. Based on geometry, there are two types of irregularities that can be encountered in high-rise buildings. These are horizontal geometric irregularity and vertical geometric irregularity.

The present study considers the vertical geometric irregularities in selected reinforced concrete (RC) moment-resisting frames. There

Eng. H.M.S.C. Rathnasiri, B.Sc. Eng. (Hons) (SLIIT), AMIE (Sri Lanka)

Email:saharshac@gmail.com

(iD) http://orcid.org/0000_0003_4464_1638

Eng. (Dr.) J.A.S.C. Jayasinghe, B.Sc. Eng. (Hons.) (Peradeniya), M.Eng.(AIT), Ph.D. (University of Tokyo)., AMIE (Sri Lanka), Senior Lecturer, Department of Civil Engineering, University of Peradeniya.

Email:supun0chamara@gmail.com

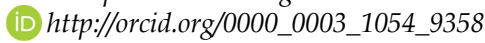

Eng. (Dr.) C.S. Bandara, B.Sc. Eng. (Peradeniya), MSc.Eng.(Peradeniya), Ph.D. (Peradeniya), C.Eng., MIE (Sri Lanka), Senior Lecturer, Department of Civil Engineering, University of Peradeniya.

Email:csbandara@eng.pdn.ac.lk

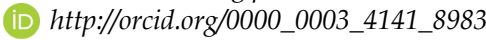


are number of past studies on quantifying the degree of irregularity in irregular building frames such as Karavasilis et al.[4], Roy \& Mahato [5], Sarkar et al.[6], Varadharajan et al.[7] and Bhosale et al.[8]. Past studies have quantified the degree of irregularity in vertically irregular reinforced concrete and steel buildings based on the geometric configurations and using dynamic parameters. Therefore, an effort has been made in the present study to quantify the degree of geometric irregularity using a proposed index based on dynamic characteristics such as base shear of fundamental mode, for the selected vertically irregular RC buildings. Fundamental mode is the mode that has the lowest natural frequency that can be extracted by performing modal analysis. The performance comparison of the existing irregularity quantification methods is also carried out for the same set of selected vertically irregular RC buildings.

\section{Quantification of Irregularities}

Table 1 presents a summary of the existing irregularity indices proposed by past studies to quantify the degree of irregularity in vertically irregular buildings. All the indices from the past studies are based on the geometric configuration of the building frame and dynamic characteristics such as first mode participation factor, natural frequency of vibration, and modal mass of the frame.

\subsection{Indices Based on Geometric Configuration}

Karavasilis et al.[4] investigated the influence of changes in setback configurations, the number of stories on the height-wise distribution, and amplitude of inelastic deformation demands of plane steel moment-resisting frames with setbacks. A family of 40 geometrical irregularities as shown in Figure1 was selected by Karavasilis et al.[4] as setback configurations of the study with 3 different stories $(3,6,9)$ as story configurations.

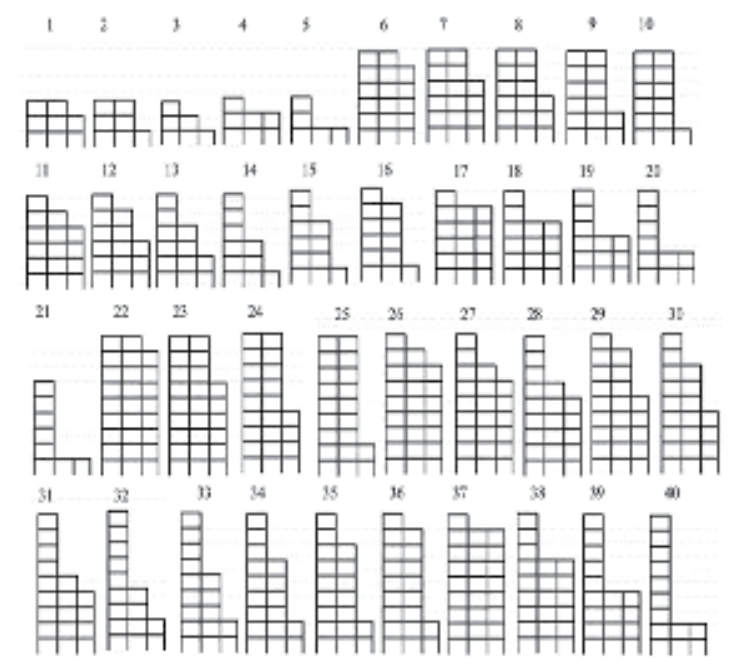

Figure 1 - Geometries of the selected setback frames by Karavasilis et al.[4]

Table 1 - Published literature on quantifying the irregularities

\begin{tabular}{|c|c|c|c|c|}
\hline Reference & Frame Type & $\begin{array}{l}\text { Index } \\
\text { Type }\end{array}$ & \multicolumn{2}{|l|}{ Index Equation } \\
\hline Karavasilis et al.[4] & $\begin{array}{l}\text { Steel MRF with } \\
\text { setback }\end{array}$ & Geometric & $\begin{aligned} \varphi_{s} & =\frac{1}{n_{s}-1} \sum_{1}^{n_{S}-1} \frac{L_{i}}{L_{i+1}} \\
\varphi_{b} & =\frac{1}{n_{b}-1} \sum_{1}^{n_{b}-1} \frac{H_{i}}{H_{i+1}}\end{aligned}$ & $\begin{array}{l}\text { Eq.(1) } \\
\text { Eq.(2) }\end{array}$ \\
\hline Roy \& Mahato [5] & $\begin{array}{l}\text { RC Setback } \\
\text { frame }\end{array}$ & Geometric & $\varphi_{\text {avg }}=\frac{\varphi_{s}+\varphi_{b}}{2}$ & Eq.(3) \\
\hline Sarkar et al.[6] & $\begin{array}{l}\text { RC Stepped } \\
\text { frame }\end{array}$ & Dynamic & $\eta=\frac{\Gamma_{1}}{\Gamma_{1, r e f}}$ & Eq.(4) \\
\hline Varadharajan et al.[7] & $\begin{array}{l}\text { RC MRF with } \\
\text { setbacks }\end{array}$ & Dynamic & $\lambda_{r}=\sum_{1}^{k} \frac{\omega_{i r}}{\omega_{r}}$ & Eq.(5) \\
\hline Bhosale et al. [8] & RC MRF & Dynamic & $\begin{array}{l}\text { Effective modal mass and } \\
\text { participation fact }\end{array}$ & node \\
\hline
\end{tabular}

NOTE: $\mathrm{n}_{\mathrm{s}}$ is number of stories; $\mathrm{n}_{\mathrm{b}}$ is number of bays; $\Gamma_{1}$ is the $1^{\text {st }}$ mode participation factor of stepped frame and $\Gamma_{1, \text { ref }}$ is the $1^{\text {st }}$ mode participation factor for a similar regular frame; $\omega_{i r}$ and $\omega_{r}$ are the modal combinations of the frequency of vibration of the irregular and regular building frames from $1^{\text {st }}$ mode to $\mathrm{k}^{\text {th }}$ mode. 


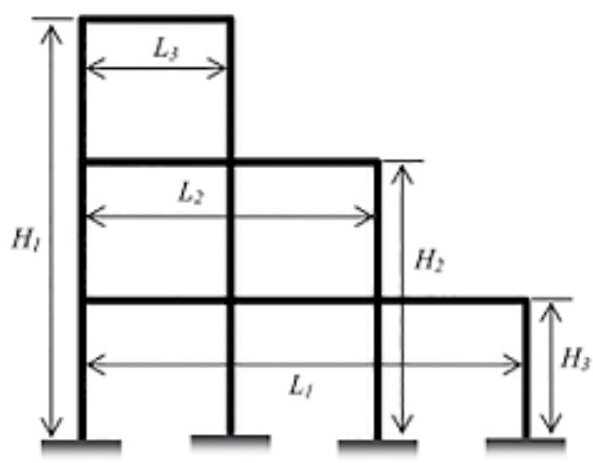

Figure 2 - Geometry definition for indices proposed by Karavasilis et. al.[4]

The indices proposed by Karavasilis et al.[4] to quantify the setback irregularity in steel moment-resisting setback frames are given by Eqs.(1) \& (2). In Eq.(1) and Eq.(2), $\mathrm{n}_{\mathrm{s}}$ is the number of stories of the frame, and $n_{b}$ is the number of bays of the first story of the frame as shown in Figure 2.

Karavasilis et al.[4] have identified that geometric irregularities in different setback configurations can be effectively captured by considering values of both indicators $\varphi_{s}$ and $\varphi_{b}$. The proposed indices are equal to unity for regular frames without setback irregularity while higher values of $\varphi_{s} \& \varphi_{b}$ indicate the large reduction in floor areas and tower-like structures respectively.

Roy \& Mahato [5] studied the applicability of the equivalent lateral force method for reinforced concrete moment resisting frames with setback irregularity using rigid and flexible diaphragm models. Selected reinforced concrete frames with different setback configurations and story configurations have been shown in Figure 3.

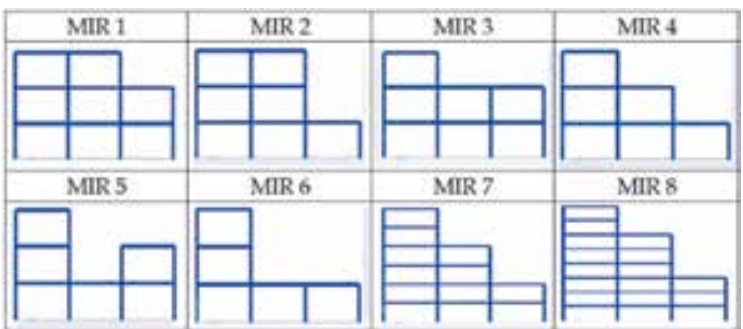

Figure 3 - Geometries of the selected setback frames by Roy \& Mahato[5]

Roy \& Mahato [5] proposed an irregularity index based on the irregularity indices presented by Karavasilis et al.[4] to quantify the irregularity in reinforced concrete setback frames as given by Eq. (3) where $\varphi_{s} \& \varphi_{b}$ are the indices proposed by Karavasilis et al.[4].
The irregularity index has been computed for the selected setback frames and presented in Table 2. It has been identified that the proposed approach by Roy \& Mahato [5] can well quantify the different setback irregularities compared to the approach proposed by Karavasilis et al.[4].

Karavasilis et al.[4] have limited their irregularity index only for the steel moment resisting setback frames. However, Roy \& Mahato [5] evaluated the performance of the Karavasilis et al.[4] irregularity indices considering the concrete moment-resisting frames. It can be identified that the degree of irregularity by Karavasilis et al.[4] approach for the setback frames of MIR4 and MIR5 is the same. This can be identified as a drawback of the Karavasilis et al.[4] approach. Roy \& Mahato [5] index also shows similar behavior for the setback frames of MIR2 \& MIR3 and MIR4 \& MIR5.

Table 2 - Data pertinent to selected setback frames by Roy \& Mahato [5]

\begin{tabular}{|c|c|c|c|c|}
\hline \multirow{2}{*}{ No. } & \multirow{2}{*}{$\begin{array}{c}\text { Model } \\
\text { Identification }\end{array}$} & \multicolumn{3}{|c|}{ Irregularity Index } \\
\cline { 3 - 5 } & & $\boldsymbol{\varphi}_{\boldsymbol{s}}$ & $\boldsymbol{\varphi}_{\boldsymbol{b}}$ & $\boldsymbol{\varphi}_{\text {avg }}$ \\
\hline $\mathbf{1}$ & MIR1 & 1.25 & 1.25 & 1.25 \\
\hline $\mathbf{2}$ & MIR2 & 2.00 & 1.25 & 1.63 \\
\hline $\mathbf{3}$ & MIR3 & 1.25 & 2.00 & 1.63 \\
\hline $\mathbf{4}$ & MIR4 & 1.75 & 1.75 & 1.75 \\
\hline $\mathbf{5}$ & MIR5 & 1.75 & 1.75 & 1.75 \\
\hline $\mathbf{6}$ & MIR6 & 2.00 & 2.00 & 2.00 \\
\hline $\mathbf{7}$ & MIR7 & 1.75 & 1.30 & 1.53 \\
\hline $\mathbf{8}$ & MIR8 & 1.52 & 1.19 & 1.36 \\
\hline
\end{tabular}

Sarkar et al.[6] and Varadharajan et al.[7] found that, even though methods proposed by Karavasilis et al.[4] and Roy \& Mahato [5] can well quantify the geometric irregularities in setback moment-resisting frames, vertical irregularities such as in-plane discontinuity in floating column moment-resisting frames and irregularities in stiffness and strength in open ground story moment-resisting frames cannot be well quantified. 


\subsection{Indices Based on Dynamic Characteristics}

Many published studies attempt to quantify the degree of irregularity in vertically irregular buildings using dynamic parameters such as first mode participation factor, natural frequency of vibration, and modal mass of the frame evaluated by modal analysis.

Sarkar et al.[6] proposed a new approach for quantifying the degree of irregularity, only for stepped buildings using elastic modal properties. This index considers the degree of irregularity in stepped buildings by considering the mass and stiffness distribution of the system. Irregularities in the stepped frames can be effectively captured by the relative first mode participation factor. Regularity index $(\eta)$ is proposed by Sarkar et al.[6] to quantify the irregularity of the stepped frame according to Eq.(4). In Eq.(4), $\Gamma_{1}$ is the $1^{\text {st }}$ mode participation factor for the RC stepped frame under consideration and $\Gamma_{1, \text { ref }}$ is the $1^{\text {st }}$ mode participation factor for a similar RC regular frame without steps.

Sarkar et al.[6] considered three different building geometries with different stepped irregularities at the top of the building due to the successive reduction of one bay and one step height of one story (S1), two-story (S2) and three-story (S3) as shown in Figure 4. The regular frame $(\mathrm{R})$, without any step, was also included for the analysis.

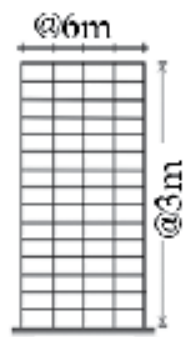

Type R

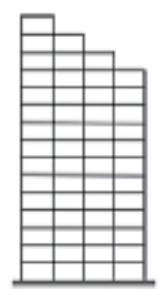

Type SI

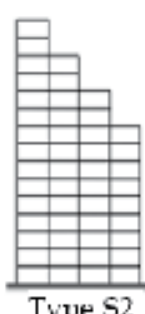

Type $\$ 2$

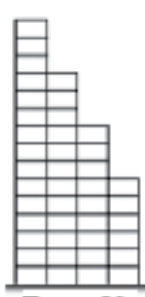

Type S3
Figure 4 - Geometries of the selected stepped frames by Sarkar et al.[6]

Sarkar et al.[6] consider the variation of the proposed regularity index with the number of stories ranging from 6-18. Table 3 shows the prescribed values for the amount of irregularity from the proposed regularity index, code defined approaches and method proposed by Karavasilis et al.[4] considering the selected types of stepped buildings frames with different story levels.
Table 3 - Data pertinent to selected setback frames by Sarkar et al.[6]

\begin{tabular}{|c|c|c|c|c|c|}
\hline \multirow{2}{*}{$\begin{array}{c}\text { Frame } \\
\text { Type }\end{array}$} & \multirow{2}{*}{$\begin{array}{c}\text { IS } \\
1893 \\
(2002) \\
\end{array}$} & \multirow{2}{*}{$\begin{array}{c}\text { ASCE } \\
7 \\
(2005) \\
\end{array}$} & \multicolumn{2}{|c|}{$\begin{array}{c}\text { Karavasilis } \\
\text { et al.[4] }\end{array}$} & \multirow{2}{*}{$\begin{array}{c}\text { Sarkar } \\
\text { et al.[6] }\end{array}$} \\
\hline & & & $\phi_{s}$ & $\phi_{b}$ & \\
\hline R-6 & 1.00 & 1.00 & 1.00 & 1.00 & 1.00 \\
\hline S1-6 & 0.75 & 2.00 & 1.37 & 1.26 & 0.84 \\
\hline S2-6 & 0.75 & 2.00 & 1.40 & 1.50 & 0.69 \\
\hline R-8 & 1.00 & 1.00 & 1.00 & 1.00 & 1.00 \\
\hline S1-8 & 0.75 & 2.00 & 1.26 & 1.17 & 0.89 \\
\hline S2-8 & 0.75 & 2.00 & 1.26 & 1.61 & 0.74 \\
\hline S3-8 & 0.75 & 2.00 & 1.29 & 1.70 & 0.65 \\
\hline R-10 & 1.00 & 1.00 & 1.00 & 1.00 & 1.00 \\
\hline S1-10 & 0.75 & 2.00 & 1.20 & 1.13 & 0.91 \\
\hline S2-10 & 0.75 & 2.00 & 1.20 & 1.36 & 0.77 \\
\hline S3-10 & 0.75 & 2.00 & 1.20 & 2.39 & 0.69 \\
\hline R-12 & 1.00 & 1.00 & 1.00 & 1.00 & 1.00 \\
\hline S1-12 & 0.75 & 2.00 & 1.17 & 1.10 & 0.94 \\
\hline S2-12 & 0.75 & 2.00 & 1.17 & 1.26 & 0.82 \\
\hline S3-12 & 0.75 & 2.00 & 1.17 & 1.61 & 0.70 \\
\hline R-15 & 1.00 & 1.00 & 1.00 & 1.00 & 1.00 \\
\hline S1-15 & 0.75 & 2.00 & 1.13 & 1.08 & 0.96 \\
\hline S2-15 & 0.75 & 2.00 & 1.13 & 1.19 & 0.89 \\
\hline S3-15 & 0.75 & 2.00 & 1.13 & 1.36 & 0.78 \\
\hline R-18 & 1.00 & 1.00 & 1.00 & 1.00 & 1.00 \\
\hline S1-18 & 0.75 & 2.00 & 1.11 & 1.06 & 0.96 \\
\hline S2-18 & 0.75 & 2.00 & 1.11 & 1.14 & 0.91 \\
\hline S3-18 & 0.75 & 2.00 & 1.11 & 1.26 & 0.82 \\
\hline
\end{tabular}

Karavasilis et al.[4] approach is better in quantifying setback irregularity than code defined approaches. However, it requires two indices to quantify the amount of irregularity in setback frames. It assumes uniform variation of mass and stiffness along with the building height and width as well. However, the proposed index by Sarkar et al.[6] effectively captures the irregularity caused due to various geometrical stepped configurations considered in the study. Figure 5 shows the variation of the regularity index with the number of stories for the stepped building types S1, S2, and S3.

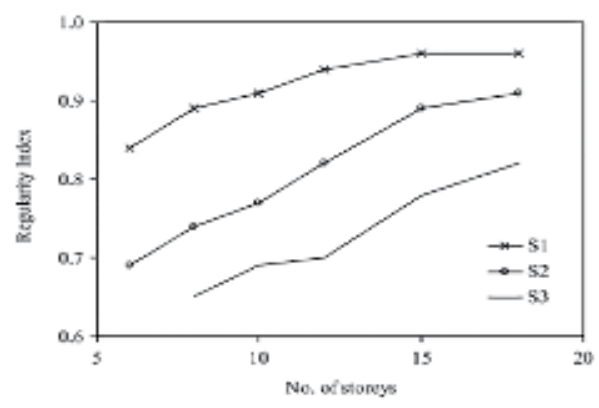

Figure 5 - Variation of regularity index with number of stories by Sarkar et al.[6]. 
It can be noted that the regularity index increases with an increase in the number of stories, the rate of increase being stiffer when the number of stories per step increases. For any given number of stories, the regularity index is the least when the number of stories per step is largest. Thus, it can be identified that regularity index can effectively capture the irregularity caused due to the various geometrical stepped configurations.

Accordingly, Varadharajan et al.[7] introduced a parameter called 'irregularity index' that is based on dynamic characteristics of the frame to quantify the setback irregularity. The natural frequency of vibration and mass participation factors are important dynamic characteristics of buildings under seismic excitation. Therefore, the irregularity index to quantify the setback irregularity is proposed as givenby Eq.(5).

In Eq.(5), $\omega_{i r}$ and $\omega_{r}$ are the modal combinations of the frequency of vibration of the irregular and regular building frames from $1^{\text {st }}$ mode to $k^{\text {th }}$ mode. Figure 6 shows the selected setback configurations by Varadharajan et al.[7] for their study.

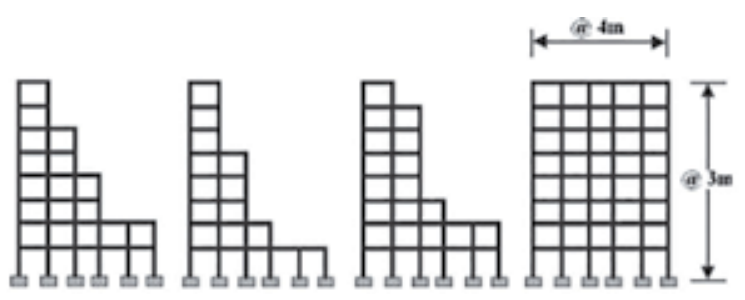

Figure 6 - Geometries of the selected setback frames by Varadharajan et al.[7]

Table 4 shows a comparison made by Varadharajan et al.[7], to compare the degree of irregularity from the proposed irregularity index, code defined approaches and method proposed by Karavasilis et al.[4], considering the selected types of setback buildings frames.

Table 4 - Data pertinent to selected setback frames by Varadharajan et al.[7]

\begin{tabular}{|c|c|c|c|c|c|c|c|}
\hline \multirow[t]{2}{*}{$\begin{array}{l}\dot{Z} \\
\dot{\boldsymbol{z}}\end{array}$} & \multirow[t]{2}{*}{ 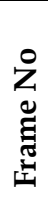 } & \multirow{2}{*}{ 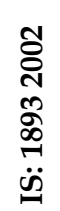 } & \multirow[t]{2}{*}{ 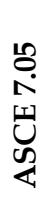 } & \multirow[t]{2}{*}{ 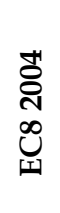 } & \multicolumn{2}{|c|}{ 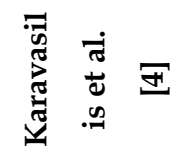 } & \multirow[t]{2}{*}{ 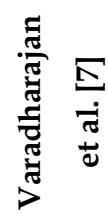 } \\
\hline & & & & & $\phi_{s}$ & $\phi_{b}$ & \\
\hline 1 & A & 0.6 & 2 & 0.5 & 1.22 & 2.66 & 0.53 \\
\hline 2 & B & 0.6 & 2 & 0.5 & 1.45 & 2.66 & 0.46 \\
\hline 3 & $\mathrm{C}$ & 0.6 & 2 & 0.5 & 1.21 & 2.66 & 0.58 \\
\hline 4 & $\mathrm{D}$ & 0.6 & 1 & 1.0 & 1.14 & 2.66 & 1.00 \\
\hline
\end{tabular}

It can be noted that code defined approaches prescribe the same irregularity limit for all different setback configurations considered in the study. Therefore, code defined approaches are not effective in quantifying the degree of irregularity in setback buildings. A review study done by Roy and Chakroborty [10] has also confirmed this fact. Karavasilis et al.[4] approach is better in quantifying setback irregularity than code defined approaches. However, it requires two indices to quantify the degree of irregularity in setback frames. Also, it assumes uniform variation of mass and stiffness along with the building height and width. However, the proposed approach by Varadharajan et al.[7] requires only a single parameter to account for the degree of irregularity in setback irregularity and performs better on quantifying the degree of irregularity compared to code defined approaches and published literature.

Bhosale et al.[8] considered the adequacy of effective modal mass and first mode participation factor on quantification of the degree of irregularity in reinforced concrete stepped frames, setback frames, open ground story frames, and floating column frames as shown in Figure 7. RC regular frame (R), without any vertical irregularity, was also included for the analysis.

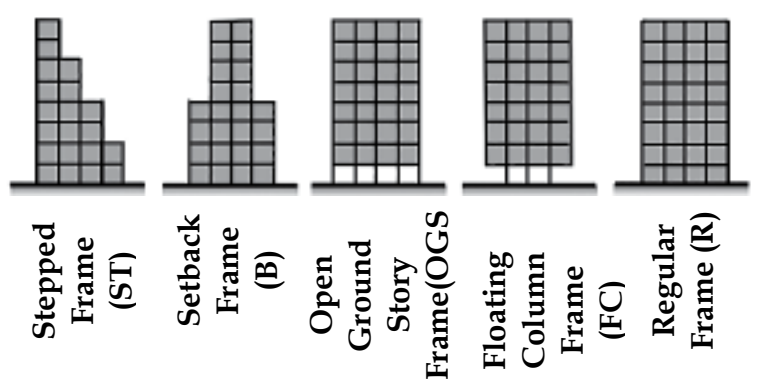

Figure 7 - Geometries of the selected irregular frames by Bhosale et al.[8]

A modal analysis that was carried out to determine the first mode participation factor for selected irregular frames is shown in Figure 8.

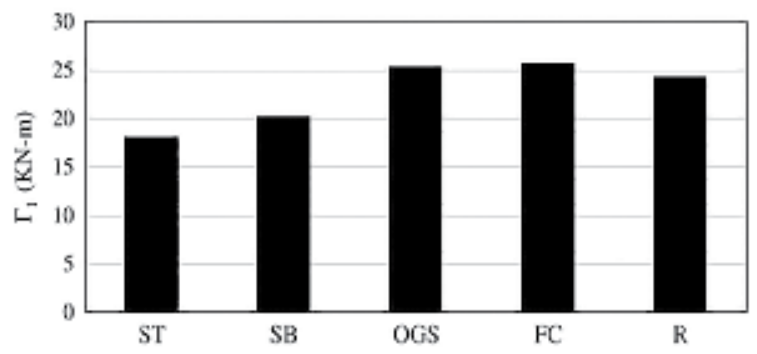

Figure 8 - First mode participation factor selected irregular frames by Bhosale et al.[8] 
Bhosale et al.[8] noted that first mode participation factor for setbacks (SB) and stepped (ST) frames are lesser than the regular frame (R), but open ground story (OGS) and floating column (FC) frames have a modal participation factor which is slightly higher than the regular frame (R). Since, first mode participation factor can depict a significant difference for each selected vertically irregular frame, first mode participation factor can be considered as an acceptable indicator for quantifying vertical irregularity.

The effective modal mass for the first mode $\left(M_{1}^{*}\right)$ for selected vertically irregular frames is shown in Figure 9.

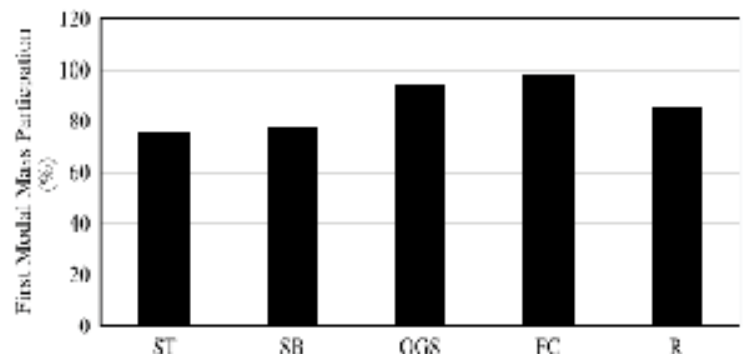

Figure 9 - First mode mass participation for irregular frames by Bhosale et al.[8]

Bhosale et al.[8] noted that effective modal mass for the first mode also follows the behavior similar to the behavior of the first mode participation factor. This means that the effective modal mass for the first mode also has a good relationship with the irregularity of the building.

The degree of irregularity in open ground story frames and floating column frames considered by Bhosale et al.[8] cannot be well quantified using the irregularity indices proposed by Karavasilis et al.[4] and Roy \& Mahato [5], because their approaches cannot capture the mass and stiffness variations within the moment-resisting frame. Irregularities due to the mass and stiffness variations can be only captured by adopting the irregularity indices based on dynamic characteristics.

\section{Proposed Index}

According to the past studies, vertical irregularities due to the non-uniform distribution of the mass, stiffness, and strength along the height of the building can be effectively captured by the irregularity indices based on the dynamic characteristics such as first mode participation factor, natural frequency of vibration, modal mass of the frame, because dynamic analysis considers the mass and the stiffness distribution of the system which affect the irregularity of the building. Past studies considered the first mode participation factor, frequency of vibration, and modal mass participation for the quantification of the vertical irregularities. However, base shear, base moment, and modal stiffness are also dynamic characteristics that can be adopted in the quantification of vertical irregularities. Therefore, first mode base shear is considered in the present study to define a new irregularity index for the quantification of vertical geometric irregularities in RC momentresisting frames.

The lateral force at the base of a structure is termed as base shear. Computation of the base shear due to an earthquake event depends on soil conditions at the site, probability of significant seismic ground motion, the level of ductility and over strength associated with various structural configurations, total weight of the structure, the period of vibration when subjected to dynamic loading, etc. Since the computation of the fundamental period of vibration considers the distribution of the mass and stiffness of the frame, fundamental mode base shear is adopted in the present study to quantify the degree of irregularity in selected RC moment-resisting frames.

Irregularities in selected vertically irregular RC frames as shown in Figure 10 can be effectively captured by considering the ratio of fundamental mode base shear of the regular frame to the fundamental mode base shear of the irregular frame. Design details of the selected moment-resisting frames have been discussed under structural modeling. Accordingly, the irregularity index $(\psi)$ is proposed to quantify the degree of irregularity in plain RC vertically irregular momentresisting frames as given by Eq.(6),

$$
\text { Irregularity Index }(\psi)=\frac{V_{f, \text { regular }}}{V_{f, \text { irregular }}}
$$

where, $V_{f}$, irregular is the fundamental mode base shear of the irregular frame and $V_{f}$, regular is the fundamental mode base shear of a similar regular frame without any irregularities. The Irregularity Index $(\psi)$ value of unity represents a frame without any vertical geometric irregularities and higher or lower values represent the irregular frames compared to the reference regular frame. Linear modal analysis is performed using the FEM software SAP2000 
to compute the fundamental mode base shear. FEM calculates the fundamental mode base shear according to Eq.(7) given in Uniform Building Code [11].

$$
V=\frac{1.25 Z . I . S}{R_{w} T^{\frac{2}{3}}} W
$$

where, " $Z$ " is the seismic zone factor and " $S$ " is a coefficient that depends on the soil condition of the site, " $I$ " is the importance factor that can be obtained from the code, " $T$ " represents the fundamental period of the building frame and " $\mathrm{R}_{\mathrm{W}}$ " is a numerical coefficient. " $\mathrm{W}$ " stands for the weight of the building frame and " $V$ " is for the base shear for the fundamental mode.

\section{Numerical Example}

Selected vertically irregular moment resisting frames for the present study are setback frames (SB), stepped frames (ST) representing vertical geometric irregularity, and floating columns (FC) representing in-plane discontinuity. Regular frame (R) is also considered as a reference frame in the study. Figure 10 shows the schematic diagrams of selected vertically irregular building frames considered in the present study.

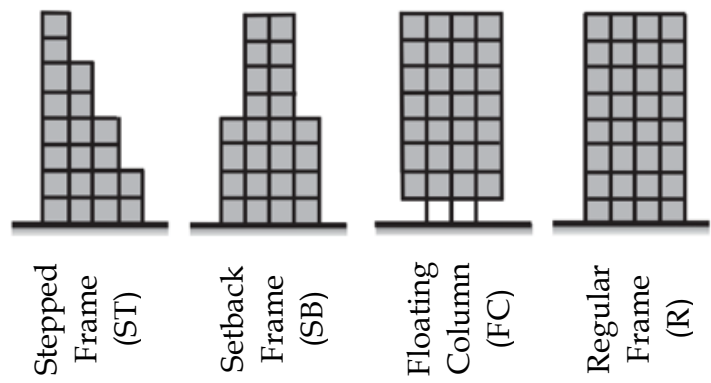

Figure 10 - Selected vertically irregular frames considered in the study

All the selected moment-resisting frames shown in Figure 10 are G+7 storied having 4 bays with a uniform bay width of $5 \mathrm{~m}$ and a uniform story height of $3.2 \mathrm{~m}$. Design details of the regular reinforced concrete momentresisting frame have been obtained by a past study done by Haran Pragalath et al.[12] according to IS1893 (2002) [13]. Dolsek \& Fajfar [14], Celarec et al.[15], Hashmi and Madan [16], Fiore et al.[17] and Bolea [18] also presented the same design details similar to the Haran Pragalath et al.[12] for the regular RC momentresisting frame considered in the present study. According to Haran Pragalath et al.[12], breadth and depth of the columns and beams are $400 \mathrm{~mm} \times 400 \mathrm{~mm}$ and $300 \mathrm{~mm} \times 400 \mathrm{~mm}$, respectively. The characteristic strength of concrete is taken as $25 \mathrm{MPa}$. The regular moment-resisting frame has been designed for the highest seismic zone of India with peak ground acceleration (PGA) of $0.36 \mathrm{~g}$ as per IS 1893 (2002) [13] considering the medium soil condition. Selected irregular frames are obtained by modifying the geometry of the designed regular frame, and analysis has been carried out using FEM software SAP 2000. The reason for maintaining the same design details for all the selected irregular frames is that the study is not to compare the design procedure for vertically irregular buildings but to evaluate the degree of irregularity in vertically irregular reinforced concrete frames to a similar kind of regular $(\mathrm{R})$ frame.

\section{Results \& Discussion}

Table 5 shows the calculated values for the fundamental base shear and proposed irregularity index $(\psi)$ for the different types of in-plain RC moment resisting frames considered in the study.

Table 5 - Base shear and irregularity index for frame types

\begin{tabular}{|c|c|c|}
\hline Frame Type & $\begin{array}{c}\text { Base Shear } \\
(\mathbf{k N})\end{array}$ & $\begin{array}{c}\text { Irregularity } \\
\text { Index }(\boldsymbol{\varphi )}\end{array}$ \\
\hline FC & 406 & 1.86 \\
\hline R & 758 & 1.00 \\
\hline SB & 904 & 0.84 \\
\hline ST & 952 & 0.80 \\
\hline
\end{tabular}

It can be identified that the proposed irregularity index $(\psi)$ can effectively capture the different types of vertical geometric irregularities in plain RC moment-resisting frames considered in the study. Irregularity index $(\psi)$ of the FC frame is higher than that of $\mathrm{R}$ frame and irregularity index $(\psi)$ of the SB frame and ST frame is lower than that of $R$ frame. This is due to the lower base shear demand in SB and ST frames compared to the regular frame $\mathrm{R}$ and higher base shear demand in floating column FC frames compared to the regular frame $\mathrm{R}$.

All the parameters except the natural period of the frame and weight of the building in Eq.(7) are the same for all the selected RC building frames considered in the study. Therefore, base shear of the fundamental mode for the selected building frames depends on the weight of the building frame and two-third power of the 
period of the frame. The natural period of the building can be obtained by performing a modal analysis using SAP2000 which considers the mass and stiffness distribution of the frame. Variation of the period of the fundamental mode and self-weight of the frame can be well accounted by evaluating the base shear of the fundamental mode according to Eq.(7). Based on the significant difference obtained in the fundamental mode base shear values shown in Table 5, irregularity index $(\psi)$ can be considered as a better indicator in quantifying the irregularity in selected vertically irregular $\mathrm{RC}$ frames compared to a similar kind of regular frame.

Table 6 shows the computed values for the vertically irregular $\mathrm{RC}$ frames considered in the present study for the different parameters adopted in the past studies to quantify the degree of irregularity. According to the $\varphi_{s}$ index proposed by Karavasilis et al.[4], irregularity of the selected frames varies in the form of $\mathrm{FC}<\mathrm{R}<\mathrm{SB}<\mathrm{ST}$. However, $\varphi_{b}$ index of Karavasilis et al.[4] is the same for all the irregular frames. Therefore, it should be noted that $\varphi_{b}$ index of Karavasilis et al.[4] is not effective in quantifying the vertical geometric irregularities in selected reinforced moment resisting frames.

According to the Roy \& Mahato [5] index, irregularity varies in the form of $\mathrm{FC}<\mathrm{R}<\mathrm{SB}<\mathrm{ST}$.
It should be noted that, considering the values obtained for the $\varphi_{s} \& \varphi_{b}$ indices alone, irregularity cannot be well quantified. Since Roy \& Mahato [5] proposed a single parameter, it can quantify the degree of irregularity in selected vertically irregular RC frames better than the indices proposed by Karavasilis et al.[4].

Karavasilis et al.[4] and Roy \& Mahato [5] proposed their irregularity indices for vertical geometrical irregularities in moment-resisting setback frames only. However, the present study considers not only the vertical geometric irregularities in RC stepped frames and RC setback frames, but some other vertical irregularities such as in-plane discontinuity in RC floating column frames as well. However, computed values for the selected vertically irregular frames by Karavasilis et al. [4] indices and Roy \& Mahato [5] index are approximately the same. Therefore, irregularity indices which depend on the geometric configuration alone cannot be utilized to quantify the degree of irregularity in vertically irregular reinforced concrete moment-resisting frames.

Therefore, Sarkar et al.[6] proposed a new approach based on the dynamic characteristic such as $1^{\text {st }}$ mode participation factor to quantify the regularities in vertically irregular momentresisting frames. Irregularities of the momentresisting frames considered in the present study

Table 6 - Performance of the existing irregularity indicators

\begin{tabular}{|c|c|c|c|c|c|c|}
\hline \multirow{2}{*}{ 芯 } & \multirow{2}{*}{ Literature } & \multirow{2}{*}{ Irregularity Index } & \multicolumn{4}{|c|}{ Frame Types } \\
\hline & & & FC & $\mathbf{R}$ & SB & ST \\
\hline \multirow{3}{*}{ 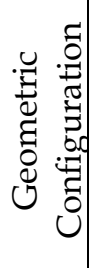 } & \multirow{2}{*}{ Karavasilis et al.(2008) } & $\varphi_{s}$ & 0.93 & 1.0 & 1.14 & 1.26 \\
\hline & & $\varphi_{b}$ & 1.14 & 1.17 & 1.17 & 1.17 \\
\hline & Roy \& Mahato(2013) & $\varphi_{\text {avg }}$ & 1.035 & 1.085 & 1.155 & 1.215 \\
\hline \multirow{5}{*}{ 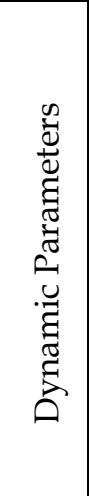 } & Sarkar et al.(2010) & $\frac{1}{\eta}$ & 1.02 & 1.00 & 1.19 & 1.32 \\
\hline & Varadharajan et al.(2013) & $\lambda_{r}$ & 0.88 & 1.000 & 0.991 & 0.986 \\
\hline & \multirow{2}{*}{ Bhosale et al.(2017) } & $\begin{array}{l}\text { First Mode Modal } \\
\text { Participation Factor }\end{array}$ & 6.15 & 6.28 & 5.28 & 4.78 \\
\hline & & $\begin{array}{c}\text { First Mode Effective } \\
\text { Modal mass }\end{array}$ & 0.80 & 0.82 & 0.76 & 0.73 \\
\hline & Present Study & $\Psi$ & 1.86 & 1.0 & 0.84 & 0.80 \\
\hline
\end{tabular}


are compared by taking the inverse of the Sarkar et al.[6] index. Irregularity of the selected frames according to the regularity index $(\eta)$ proposed by Sarkar et al.[6] is in the form of $\mathrm{R}<\mathrm{FC}<\mathrm{SB}<\mathrm{ST}$. Therefore, it can be noted that even though regularity index $(\eta)$ is initially defined to quantify the vertical geometric irregularities in stepped frames by Sarkar et al.[6], it can well quantify the vertical geometric irregularities SB and FC frames.

Varadharajan et al.[7] also proposed a dynamic based irregularity index that shows all the irregular frames having less irregularity index compared to the regular (R) frame. This is contradicting the behavior from Sarkar et al.[6] irregularity index. Therefore, based on the computed values for the irregularity index $\left(\lambda_{r}\right)$, it should be noted that the irregularity index $\left(\lambda_{r}\right)$ cannot effectively quantify the vertical geometric irregularities in selected moment resisting frames.

Bhosale et al.[8] proposed the first mode modal participation factor and first mode effective modal mass parameters to quantify the degree of irregularity in vertically irregular RC frames compared to a similar regular RC frame. All the irregular frame types possess less first mode modal participation factor compared to the regular $(\mathrm{R})$ frame. This behavior is similar when considering the first mode effective modal mass as well. The variation of both parameters for the selected frames is $\mathrm{ST}<\mathrm{SB}<\mathrm{FC}<\mathrm{R}$. Therefore, the first mode modal participation factor and first mode effective modal mass parameters can effectively quantify the vertical irregularities in $\mathrm{RC}$ moment-resisting frames.

In the present study, fundamental mode base shear is adopted to quantify the vertical geometric irregularities and significant variation in the proposed Irregularity Index $(\psi)$ is observed for the selected vertically irregular $\mathrm{RC}$ frames. Irregularity Index $(\psi)$ for FC frames is higher than that for $\mathrm{R}$ frame. Irregularity Index $(\psi)$ for SB and ST frames is lesser than that for $\mathrm{R}$ frame. Variation of the Irregularity Index $(\psi)$ is in the form of $\mathrm{ST}<\mathrm{SB}<\mathrm{R}<\mathrm{FC}$.

In order to evaluate the performance of the proposed Irregularity Index $(\psi)$ in detail, stepped frames, setback frames and floating column frames having different degrees of irregularity are considered in the study. The computed value of the Irregularity Index $(\psi)$ for each considered stepped frame is shown in Table 7. It should be noted that according to the vertical geometry of the ST frames, irregularity of the considered stepped frames is increasing form Type-1 frame to Type-3 frame. Accordingly, Irregularity Index $(\psi)$ is also increasing from Type- 1 frame to Type-3 frame. Therefore, the variation of this geometric vertical irregularity in stepped frames has been effectively captured by the proposed Irregularity Index $(\psi)$.

Performance evaluation of the proposed Irregularity Index $(\psi)$ considered three types of setback frames as shown in Table 7. Vertical geometric irregularity of the selected setback frames is increasing from the Type- 1 frame to the Type- 3 frame and computed values of $(\psi)$ are also increasing from Type- 1 frame to the Type-3 frame. Therefore, it should be noted that Irregularity Index $(\psi)$ can effectively quantify the degree of irregularity in considered setback frames.

Irregularity Index $(\psi)$ is also computed for three types of floating column frame and shown in Table 7. According to the vertical geometry of the frame, it can be identified that vertical geometric irregularity of the floating column frame has been increased form Type-1 frame to Type-3 frame. Variation of this vertical geometric irregularity in floating column frames has been effectively captured by the Irregularity Index $(\psi)$. Therefore, it should be noted that the proposed Irregularity Index $(\psi)$ can well quantify the vertical geometric irregularities in reinforced concrete stepped frames, setback frames and floating column frames with respect to a similar regular frame.

Since dynamic parameters, which can be computed based on dynamic analysis, consider the mass and stiffness distribution of the frame, they can be adopted to define irregularity indices which can quantify the degree of irregularity in irregular reinforced concrete moment-resisting frames. It should benoted that past studies such as Sarkar et al.[6], Varadharajan et al.[7] and Bhosale et al.[8], consider the dynamic based parameters on the quantification of the vertical geometric irregularities and obtained slight variation in the considered dynamic parameter for the irregular frames considered in their analysis. However, the present study defines the Irregularity Index $(\psi)$ based on the fundamental mode base shear value and significant variation has been obtained for the different types of RC stepped frames (ST), setback frames (SB), and 
Table 7 - Performance of the proposed Irregularity Index - $(\psi)$

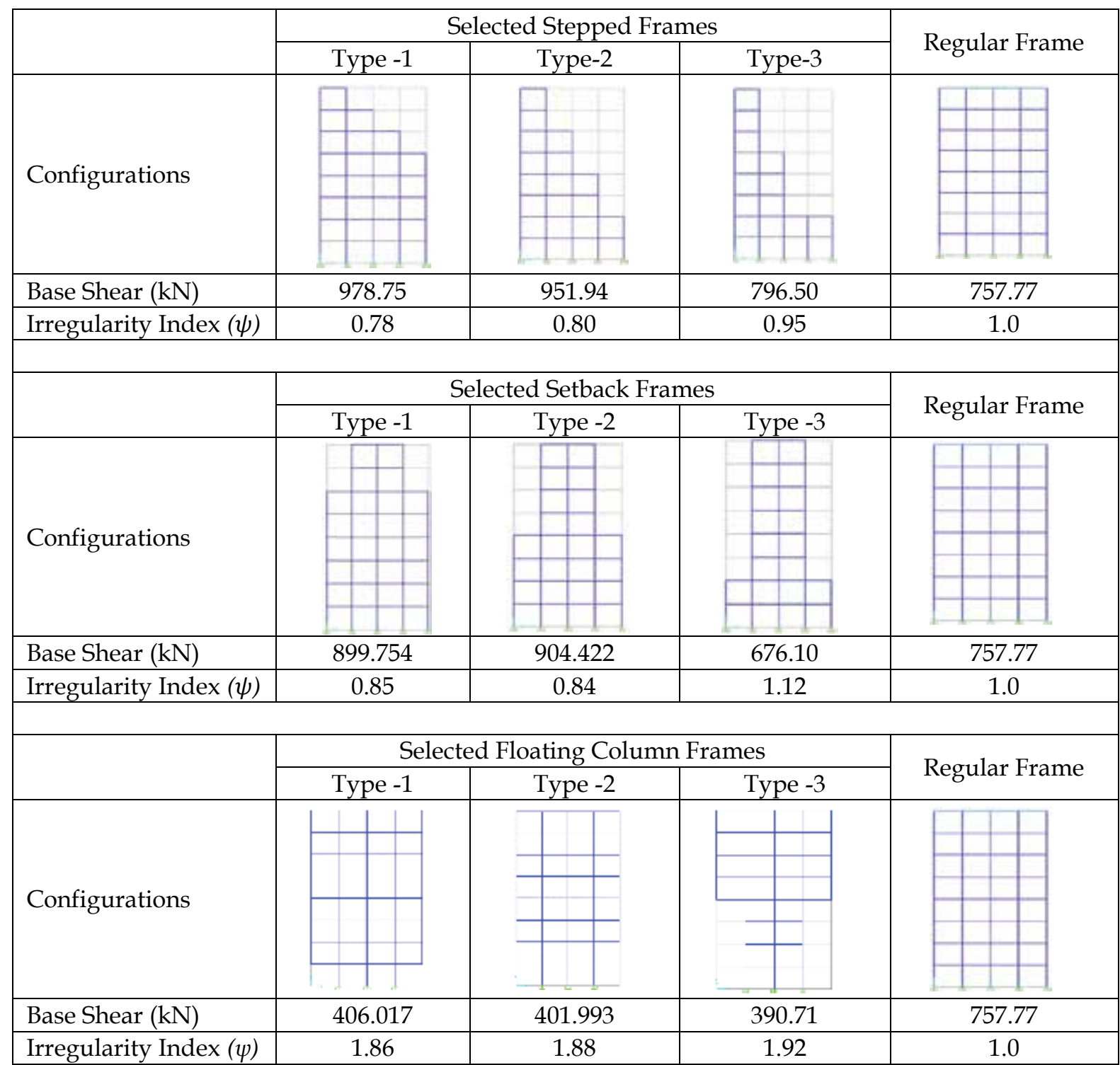

floating column frames (FC) considered in the present study as shown in Table 7 .

\section{Conclusions}

The present study considers the quantification of vertical geometric irregularities in selected reinforced concrete moment-resisting frames by introducing a new index named Irregularity Index $(\psi)$ that is based on a dynamic parameter termed as fundamental mode base shear value. Based on the numerical example, variation of the proposed Irregularity Index $(\psi)$ is in the form of $\mathrm{ST}<\mathrm{SB}<\mathrm{R}<\mathrm{FC}$. Therefore, it can be concluded that the proposed Irregularity Index $(\psi)$ can well quantify the degree of irregularity in selected reinforced concrete momentresisting stepped frames (STs), setback frames (SBs) and floating column (FCs) frames compared to the geometric and dynamic irregularity indices proposed by the past studies.

It is expected to improve the sensitivity of the proposed Irregularity Index $(\psi)$ in future studies by following a detailed modeling approach that considers the three-dimensional moment resisting frames with masonry infill walls to incorporate the actual model details into the structural model.

\section{References}

1. Georgoussis, G., Tsompanos, A., and. Makarios, T., "Approximate Seismic Analysis of Multi-story Buildings with Mass and Stiffness Irregularities," Procedia Engineering, vol. 125, pp. 959-966, 2015. 
2. Le-Trung, K., Lee, K., Lee, J., and. Lee, D. H., "Evaluation of Seismic Behaviour of Steel Special Moment Frame Buildings with Vertical Irregularities," Struct. Design Tall Spec. Build. (The Structural Design of Tall and Special Buildings), vol. 21, no. 3, pp. 215-232, 2012.

3. Michalis, F., Dimitrios, V., and Manolis, P., "Evaluation of the Influence of Vertical Irregularities on the Seismic Performance of a Nine-Storey Steel Frame," Earthquake Engineering $\mathcal{E}$ Structural Dynamics, vol. 35 , no. 12 , p. 1489 1509, 2006.

4. Karavasilis, T. L., Bazeos, N., and Beskos, D. E., "Seismic Response of Plane Steel MRF with Setbacks: Estimation of Inelastic Deformation Demands," Journal of Constructional Steel Research, vol. 64, no. 6, p. 644-654, 2008.

5. Roy, R., and Mahato, S., "Equivalent Lateral Force Method for Buildings with Setback: Adequacy in Elastic Range," Earthquakes and Structures, vol. 4, no. 6, p. 685-710, 2013.

6. Sarkar, P., Prasad, A. M., and Menon, D., "Vertical Geometric Irregularity in Stepped Building Frames," Engineering Structures, vol. 32, no. 8, p. 2175-2182, 2010.

7. Varadharajan, S., Sehgal, V., and Saini, B., "Determination of Inelastic Seismic Demands of RC Moment Resisting Setback Frames," Archives of Civil and Mechanical Engineering, vol. 13, no. 3, p. 370-393, 2013

8. Bhosale, A. S., Davis, R., and Sarkar, P., “Vertical Irregularity of Buildings: Regularity Index versus Seismic Risk," ASCE-ASME Journal of Risk and Uncertainty in Engineering Systems, Part A: Civil Engineering, vol. 3, no. 3, pp. 04017001-104017001-10, 2017.

9. Rajeev, P., and Tesfamariam, S., "Seismic Fragilities for Reinforced Concrete Buildings with Consideration of Irregularities," Structural Safety, vol. 39, p. 1-13, 2012.

10. Roy, R., and Chakroborty, S., "Seismic Demand of Plan-Asymmetric Structures: A Revisit," Earthquake Engineering And Engineering Vibration, vol. 12, no. 1, p. 99-117, 2013.

11. Uniform Building Code (1994) - Strucutral Engineering Design Provisions, California: International Conference of Building Officials.

12. Haran Pragalath, D. C., Avadhoot, B., Robin, D. P., and Pradip, S., "Multiplication Factor for Open ground storey buildings-a reliability based evaluation," Earthquake Engineering and
Engineering Vibration, vol. 15, no. 2, p. 283-295, 2016.

13. IS 1893-1 (2002): Criteria for Earthquake Resistant Design of Structures, Part 1: General Provisions and Buildings, Bureau of Indian Standard.

14. Dolsek, M., and Fajfar, P., "Soft Storey Effects In Uniformly Infilled Reinforced Concrete Frames," Journal of Earthquake Engineering, vol. 5, no. 1, pp. $1-12,2001$.

15. Celarec, D., Ricci, P., and Dolsek, M., "The Sensitivity of Seismic Response Parameters to the Uncertain Modelling Variables of MasonryInfilled Reinforced Concrete Frames," Engineering Structures, vol. 35, p. 165-177, 2012.

16. A. K. Hashmi and A. Madan, "Damage forecast for masonry infilled reinforced concrete framed buildings subjected to earthquakes in India," Current Science, vol. 94, no. 1, pp. 61-73, 2008.

17. A. Fiore, A. Netti and P. Monaco, "The Influence of Masonry Infill on the Seismic Behaviour of RC Frame Buildings," Engineering Structures, vol. 44, no. 1, p. 133-145, 2012.

18. Bolea, O., "The Seismic Behaviour of Reinforced Concrete Frame Structures with Infill Masonry in the Bucharest Area," Energy Procedia, vol. 85, p. 60-76, 2016. 